\title{
PROTECTIVE BEHAVIOUR OF RURAL CONSUMER - A CASE STUDY OF CONSUMER BEHAVIOR IN THE RURAL MARKET OF ASSAM
}

Sarmah Prasanta*1

${ }^{* 1}$ Associate Professor, Department of Accountancy, Mariani College, Mariani-785 634 *Correspondence Author: prasantsarmah@gmail.com

\section{Abstract:}

Rural Marketing is a subject that has assumed much significance in contemporary Indian Economics Studies and this is quite obvious because of the huge size of rural consuming group. The vastness of Indian Rural Market has increasingly prompted many Indian as well as multinational companies to view it as major thrust area. Unfortunately some business houses do not realize the real objectives of marketing and try to adopt all sorts of malpractices in the form of high price, deceptive practices, shoddy or unsafe products etc to serve their narrow objective of profit earning. Therefore, the rural consumer must reflect protective buying behavior in order to be free from the clutches of these sellers. In this paper an attempt has been made to examine the protective behavior of the rural consumers with the help of statistical tools like Likert scale, Chi-square test etc in order to examine the association of consumer protective behavior with variables like gender, occupation and education. And it has been found that variables namely sex, education and occupation has a bearing on the protective behavior of the consumers.

Keywords:

Rural Market, Protective Behavior, rural consumer.

\section{STATEMENT OF THE PROBLEM}

The word 'market' is derived from the Latin word 'Marcatus' which means merchandise ware, traffic trade or a place where business is conducted. (1)

According to Cornot, "Market is meant not any particular place in which things are bought and sold, but the whole of any region in which the buyers and sellers are in such free intercourse with one another that the price of the same goods tends to equality easily and quickly."(2)

According to Chapman, "the term market refers not a place but to a commodity or commodities and buyers and sellers who are in direct competition with one another."(3)

According to Clark and Clark, "A market is a centre about which or an area in which the forces leading to exchange or title to a particular product operate and towards which the actual goods tend to travel."(4)

A study of the above definitions reveals that there is considerable difference in approach as to what constitute a market among different authors. Therefore, for the purpose of this study one can define market as a physical place where buyers and sellers get together, a transfer of title of commodities or services take place. 


\section{INTERNATIONAL JOURNAL of RESEARCH -GRANTHAALAYAH \\ A knowledge Repository}

Management

According to Nations Councils of Applied Economics Research (NCAER), "A rural market is any market that exists in the rural area with a population of less than 10,000 where the aerial density of population at any population nucleation is low without any sufficient infrastructure". (5)

Rural marketing is a subject that has assumed much significance in contemporary Indian economic studies. This is quite obvious since there are about 6, 00, 000 villages in India (6). The census data reveals a clear picture about the huge size of rural consuming group. According to 2011 census report out of the total population of 121 crores, the rural population amounted to 83.3 Crores which is quite a sizeable number.

Thus the rural area presents a most fascinating challenge to the marketing men in India. The vastness of Indian rural market has increasingly prompted many Indians as well as multinational companies to view it as a major thrust area.

The goal of the marketing system is not to maximize producer's or marketer's profit but rather to maximize quality of life. Accordingly, the business houses are to pursue a policy of enlightened marketing (7) based on principles of consumer's orientation, innovation, value creation, social mission and social orientation.

Unfortunately, some business houses do not realize the objectives of marketing and try to adopt all sorts of malpractices to serve their narrow objectives of profit earning. The impact of such marketing practices on consumer welfare has been criticized on the ground of high prices, deceptive practices, high pressure selling, shoddy or unsafe products, planned obsolescence and poor services to the disadvantaged customers (8). Such consumer exploitation has become worldwide phenomenon. Consumers in developing countries particularly in India suffer more seriously from this evil practices owing to their poor bargaining power and imperfect market mechanism. The situation gets worse in the rural market in India in general and in Assam in particular because of its remote location, Lack of consumer awareness among the people and absence of voluntary organization to take up consumer related problems and inconsistent market forces.

The government of India so far enacted more than two dozen legislation to protect the interest of the consumer but due to improper implementation of the acts, the consumers are not fully secure. Writers on the field emphasize on consumer awareness and education programs as means of selfprotection by consumer themselves in various markets. $(9,10)$

The buying behavior of the consumer is a subject of utmost interest and challenging task for every marketing man. Buying behavior is all psychological, social and physical behavior of customer as they become aware of, evaluate, purchase, consume and tell others about products and services. Therefore, buyer behavior involves both individual (psychological) process and group (social) processes. Buyer behavior is reflected from awareness right through post purchase evaluation indicating satisfaction or non-satisfaction from purchases. Buyer behavior involves 


\section{INTERNATIONAL JOURNAL of RESEARCH -GRANTHAALAYAH

communications, purchasing, consumption and also redressal behavior. Consumer behavior is basically social in nature. Hence social environment plays an important role in shaping buyer's behavior. (11)

Therefore, buyer behavior includes the acts of individuals directly involved in obtaining and using economic goods and services including sequence of decision process that precedes and determines these acts. In buyer's behavior one consider not only why, how and what people buy but other factors such as where, how often and under what conditions the purchase was made.

In the above background one can come to the conclusion that the buying behavior is influenced by four factors: - buyer's characteristics (cultural, social, personal, and psychological), product characteristics (quality, price, safety, durability, freshness etc.), seller's characteristics and situational characteristics (12). The above characteristics have been discussed at length by various authors from the viewpoint of economic and marketing decision making. But how these factors interact to obtain protective behavior by which the buyer can safeguard himself against exploitation is also of academic interest.

\section{OBJECTIVES}

In the light of above discussion an attempt is made here to analyze the consumers protective behavior as a product of personal and social characteristics, accordingly the objective of the study are:-

(i) To measure the extent of protective behavior exhibited by the rural consumers against exploitation in the rural market in Assam.

(ii) To study the degree of association between his social status particularly gender, educational and occupational status.

\section{HYPOTHESIS}

In the rural market of Assam, the sellers, product characteristics and also situational Characteristics are not conducive to safeguard the interest of the consumers. Hence, the buyer himself has to play a vital role. It will be interesting to know whether the protective behavior of consumer is influenced by his socio-personal Characteristics. Accordingly a hypothesis may be stated as followsThe consumer's protective behavior is independent of his socio-cultural status.

\section{INTRODUCTION OF THE STUDY AREA}




\section{INTERNATIONAL JOURNAL of RESEARCH -GRANTHAALAYAH \\ A knowledge Repository}

Management

The area of the study of periodic rural markets is from the Jorhat district of Assam. Assam is one of the important States of North East India.

The state is divided into twenty seven districts. Jorhat is located in the central part of Assam Valley. The district is bordered by Sonitpur and Lakhimpur district in the North and Naga Hills in the South. In the Western side of the districts, there lies Golaghat district while Sibsagar district is situated to the East.

\section{METHODOLOGY}

Keeping in view the objectives of the study, it is proposed to carry out the investigation and to collect the data in three ways-

1. By collecting the information through questionnaire.

2. Through personal discussion and interviews.

3. Through published materials.

To have a cross section of opinion two rural markets were taken up for the study. They are Cinamara and Nakachari markets. A structured questionnaire was administered to the two hundred fifty consumers drawn on random basis.

The distribution of schedule was in the following manner:-

Cinamara Market- 150

Nakachari Market-100

The variation in the number of respondent in each market was done keeping in view the consideration of the size of the market and the number of consumers in each market. An approximate ratio of size and consumer was adopted to be approximately representative of the universe.

Moreover, proper care was taken to ensure that people from various occupation, age, gender group and educational background are included in the sample. Next consideration is that two markets selected for the study are in the transportation route.

Social scientists make use of various scaling and statistical techniques in the study of the various aspects of the society. Here in this study also it is proposed to make use of "Likert scale" to examine the level of protective behavior of the consumer.

Likert scale involves asking the respondent to respond to each of the statement in terms of several degrees and with these an imaginary scale is constructed. Each point on the scale carries a score. Response indicating the least favorable degree is given the least score and the most favorable is given the highest score. The Likert Scaling technique, thus, assigns a scale value to each of the responses. The same thing is done in respect of each and every statement. This way the instrument yields a total score for each respondent which would than measure the respondent's favorableness towards the given point of view. (13) 


\section{INTERNATIONAL JOURNAL of RESEARCH -GRANTHAALAYAH \\ A knowledge Repository}

Management

In order to make use of Likert Scale, the questionnaire is proposed to consist of two parts:-

1. Personal information including name, age, sex, qualification, and occupation,

2. Indicators of protective behavior such as-

(a) Checking date of manufacture and expiry.

(b) Checking marked price.

(c) Insisting to accept marked price.

(d) Comparing price in different shops.

(e) Demanding cash memos.

(f) Discussing or consulting with friends and neighbors.

(g) Checking I.S.I., F.P.O., AGMARK.

(h) Bargaining to reduce price.

(i) Comparing prices of different size, weight and volume.

(j) Effort to return defective products.

(k) Preparing monthly budget.

(l) Acquiring knowledge of consumer interest. (14)

The respondents were requested to indicate the level of their protective behavior with each of the above twelve indicators. The responses were measured on five point Likert scale with anchorsalways, very often, sometimes, rarely and never and the scores ranged from four to zero. For analysis the consumers were classified into four classes such as high, average, low, very low on the basis of their mean scores, three to four, two to three, one to two and zero to one respectively.

For studying association between consumer protective behavior and each of the social status indicator, tables were prepared taking the mean score horizontally and social dimensions vertically and the hypothesis was tested by using $\mathrm{x}^{2}$ (chi-square) at 5 P.C. level of significance.

Chi-square test is an important statistical tool in the hands of social scientist. The Chi-square test enables us to explain whether or not two attributes are associated. In a calculation of chi-square we first calculate the expected frequencies and then workout the value of $x^{2}$. If the calculated value of $x^{2}$ is greater than its table value, our inference than would be that the two attributes are associated and the association is not because of chance factor but it exists in reality. (15)

\section{CONSUMER PROTECTIVE BEHAVIOR}

In a developing state like Assam the common rural consumers are operating in a sellers market being vulnerable to a wide range of exploiting practices. There is not going to be much change in the behaviour of exploiting producers and sellers who will continue to direct their intelligence and research to find new ways of cheating. The plethora of consumer legislation could not fully succeed in curbing the exploitation and it will be optimistic to expect a complete solution to the problem through such legislations. Hence, a lasting solution lies in the form of self-protection by the consumers. This calls for protective behaviour while buying goods and services by the rural consumers in the market. Therefore, an attempt is made in the chapter to measure the extent of protective behaviour exhibited by the consumer against exploitation in the rural markets of the study area. 


\section{INTERNATIONAL JOURNAL of RESEARCH -GRANTHAALAYAH

To measure the extent of protective behaviour, likert scale technique was applied. The respondents were requested to indicate the level of their protective behaviour with each of the twelve indicators. (Table 1.1) the responses were measured on a five point likert scale with anchors- always, very often, sometimes, rarely and never and scores range from 4 to o respectively. For analysis the consumers were classified in the four classes - high, average, low, very low on the basis of their mean scores- 3 to 4,2 to 3,1 to 2 and 0 to 1 respectively.

From the distribution of mean scores against various selected indicators as depicted by table 1.1, it is revealed that the scores for preparation of monthly budget is the lowest at only 0.583 whereas that of comparing prices in different shops is highest, recording at 2.242 five indicators including checking expiry date, marked price, comparing prices, bargaining and returning defective products could obtain mean scores between two and three(average) where as the rest of the indicators except preparation of monthly budget could secure a score within the range of one and two(low). Another interesting feature is that against no indicator the mean score was above three (high range).

Table 1.1:Distribution of mean scores against consumers behavioural indicators

\begin{tabular}{|l|l|}
\hline Consumers behavioural indicators & Mean scores \\
\hline Checking date of manufacture and expiry & 2.175 \\
\hline Checking market price & 2.158 \\
\hline Insisting to accept market price & 1.783 \\
\hline Comparing prices at different shops & 2.242 \\
\hline Demanding cash memos & 1.858 \\
\hline Discussing or consulting with friends and neighbours & 1.800 \\
\hline Checking ISI, FPO,AGMARK & 1.783 \\
\hline Bargaining to reduce prices & 2.142 \\
\hline Comparing prices at different size, weight and volume & 1.853 \\
\hline Effort to return defective product & 2.058 \\
\hline Preparing monthly budget & 0.583 \\
\hline Acquiring knowledge of consumer interest & 1.208 \\
\hline
\end{tabular}

Therefore, one can come to the conclusion from the above finding that the rural consumers have not exhibited the desired protective behaviour, as a result the rural consumers are still deceived by 


\section{INTERNATIONAL JOURNAL of RESEARCH -GRANTHAALAYAH

the sellers in the form of various fraudulent practices. It will not be optimistic to except that rural consumers should be more alert and more cautions towards safeguard their own interest against exploitation in the rural market.

The distribution of consumers on the basis of sex and their exhibition of protective behaviour by way of secured score is shown in the following table-

Table 1.2: Sex Wise Distribution of Consumers

\begin{tabular}{|c|c|c|c|c|c|}
\hline \multirow{2}{*}{ Sex } & \multicolumn{4}{|c|}{ Scores } & \multirow{2}{*}{ Total } \\
\cline { 2 - 5 } & Very low & Low & Average & High & \\
\hline Male & $18(16.67)$ & $48(44.44)$ & $33(30.55)$ & $9(8.33)$ & $108(100)$ \\
\hline Female & $24(16.90)$ & $50(35.21)$ & $62(43.66)$ & $6(4.23)$ & $142(100)$ \\
\hline Total & $\mathbf{4 2}$ & $\mathbf{9 8}$ & $\mathbf{9 5}$ & $\mathbf{1 5}$ & $\mathbf{2 5 0}$ \\
\hline
\end{tabular}

(Figures in the bracket indicating percentage)

From the sex wise distribution of the consumers as shown in table 1.2 out of the 108 males 48 constituting 44.44 p.c. were included in the low class whereas 9(8.33) in the high class. Among 142 females 62 p.c. constituting 43.67 p.c. could be included in the average class followed by 50 p.c.(35.21) in the low class. A major part of the sample strength with almost equal percent. From both the gender groups belong to the very low class. The tables also exhibits that the female are shade more protective than the males.

The distribution of consumers on the basis of their educational status and exhibition of protective behavior is shown in the following table.

Table 1.3: Distribution of Consumers On The Basis Of Educational Status

\begin{tabular}{|c|c|c|c|c|c|}
\hline \multirow{2}{*}{ Education } & \multicolumn{4}{|c|}{ Scores } & \multirow{2}{*}{ Total } \\
\cline { 2 - 5 } & Very low & Low & Average & High & \\
\hline Under matric & $23(46.00)$ & $13(26.00)$ & $13(26.00)$ & $1(2.00)$ & $50(100)$ \\
\hline Matric & $10(13.16)$ & $46(60.53)$ & $18(23.68)$ & $2(2.63)$ & $76(100)$ \\
\hline Intermediate & $4(4.35)$ & $28(30.43)$ & $52(56.52)$ & $8(8.70)$ & $92(100)$ \\
\hline Graduate & $4(20.00)$ & $8((40.00)$ & $6(30.00)$ & $2(10.00)$ & $20(100)$ \\
\hline
\end{tabular}




\begin{tabular}{|c|c|c|c|c|c|}
\hline Post-graduate & $1(8.33)$ & $3(25.00)$ & $6(50.00)$ & $2(16.67)$ & $12(100)$ \\
\hline Total & $\mathbf{4 2}$ & $\mathbf{9 8}$ & $\mathbf{9 5}$ & $\mathbf{1 5}$ & $\mathbf{2 5 0}$ \\
\hline
\end{tabular}

(figures in the brackets indicate percentage)

The distribution of the customers on the basis of educational status and their protective behavior by way of secured scores in shown in table 1.3. it is revealed from the table that a majority of the under matriculates $(46$ p.c.) are in the very low class and are in the rest are equally distributed between the low and average classes. Among the matriculates 60.53 p.c. belong to the low class. Only $1 \& 2$ of the under matriculates and matriculates could scores above 3 p.c. to be included in the high class. Among the intermediates 56.52 p.c. belong to average group followed by 30.43 p.c. in the low class. Among the graduates 40 p.c. are in the low class followed by 30 p.c. in the average group 50 p.c. of the post graduate consumer are in the average class. The significant result of the analysis suggest that matriculates and under matriculates are poor itself protection against exploitation in the market.

Table 1.4 has been incorporated to reveal the consumer protective behavior exhibited by various occupational groups. It is evident from the table that 80 p.c. of the farmers scores very low to be included in the lowest category. Surprisingly 52.71 p.c. of the people engaged in business or profession scored between 1 and 2 and included in low class. Only 5.88 p.c. of the respondents in the private sector service belong to very low class whereas percentage belonging to the low and average class are 46.08 and 42.16 respectively the students \&housewives scored better by reflecting 57.63 p.c. to be included in the average category.

Table 1.4: Occupation and Distribution of Consumers

\begin{tabular}{|c|c|c|c|c|c|}
\hline \multirow{2}{*}{ Occupation } & \multicolumn{4}{|c|}{ Scores } & \multirow{2}{*}{ Total } \\
\cline { 2 - 5 } & Very low & Low & Average & High & \\
\hline Farmers & $24(80.00)$ & $4(13.34)$ & $1(1.33)$ & $1(3.33)$ & $30(100)$ \\
\hline Businessman & $8(17.39)$ & $24(52.17)$ & $11(23.91)$ & $3(6.53)$ & $46(100)$ \\
\hline Pvt. Sector employees & $6(5.88)$ & $47(46.08)$ & $43(42.16)$ & $6(5.88)$ & $102(100)$ \\
\hline Student and housewives & $2(3.39)$ & $20(33.90)$ & $34(57.63)$ & $3(5.08)$ & $59(100)$ \\
\hline Government servants & $2(15.38)$ & $3(23.08)$ & $6(46.16)$ & $2(15.88)$ & $13(100)$ \\
\hline Total & 42 & 98 & 95 & 15 & 250 \\
\hline
\end{tabular}

(figures in the brackets indicate percentage)

In order to study the association between consumers protective behavior and various social status viz, gender, education and occupation chi-square $\left(\mathrm{x}^{2}\right)$ technique is applied as to enable us to explain whether or not two attributes are associated. 


\section{INTERNATIONAL JOURNAL of RESEARCH -GRANTHAALAYAH \\ A knowledge Repository}

Management

The computed value of chi-square and its comparison with table value is shown in table 1.5

Table 1.5: Value of chi-square and its comparison with its table

\begin{tabular}{|c|c|c|c|}
\hline $\begin{array}{c}\text { Association of consumer } \\
\text { behavior with- }\end{array}$ & $\begin{array}{c}\text { Computed value of } \\
\text { chi-square }\end{array}$ & $\begin{array}{c}\text { Degree of } \\
\text { freedom }\end{array}$ & $\begin{array}{c}\text { Comparison with table } \\
\text { value at p.05 }\end{array}$ \\
\hline Gender status & 5.8519 & 2 & Higher \\
\hline Educational status & 70.376 & 12 & Higher \\
\hline Occupational status & 115.559 & 12 & Higher \\
\hline
\end{tabular}

Table 1.5 reveals that the computed value of chi-square is much higher than the table value at 5 p.c. level of significance and respective degree of freedom in all three variables namely gender, education and occupation. These imply that the consumer protective behavior is not independent of his gender, occupational and educational status.

The consumer protective behavior in the rural market in the Assam is associated with their gender, occupational and educational status. Thus these variables namely sex, education, and occupation has a bearing on the protective behavior of the consumer. Rural people in Assam particularly these less qualified are engaged in farming and small business and they are low scores in the study. On the other hand educated rural people who are the higher scores in the study are engaged in government and private sector undertakings.

Thus our hypothesis that 'consumer protective behavior is independent of his socio personal status' does not hold true in case of gender, educational and occupational variables.

\section{SUMMARY AND CONCLUSION}

Coming to the question that how much more potentialities exists for safeguard the interest of the consumers in the rural market so that the people in the rural area can be alert and vigilant against exploitation, there could be some specific suggestions for the purpose. Consumer education must from an integral part of any rural marketing strategy in order to provide relief to the consumers against exploitation. Despite the claim of the government functionaries about the rising percentage of literacy in the rural areas, the bulk of the rural population remains illiterate and uneducated. Mere ability to sign does not mean ability to understand the surroundings. Therefore a rural marketing strategist must concentrate on educating the consumer before plunging into rural market. The task became all the more hard because of deep-rooted pre judicious and superstitions etc. thus consumer education programme must be designed as not to hurt the sentiments of the rural population. 


\section{INTERNATIONAL JOURNAL of RESEARCH -GRANTHAALAYAH \\ A knowledge Repository}

Management

Consumer awareness is widely recognized as a social need of the day. Consumer ignorance seem to push behind the level of consumer awareness to a point where the legal support becomes ineffective. Therefore, sincere effort should be made to make the consumer aware of his right in order to safeguard his interest. The rural marketer need to care the adoption of a marketing strategy that emphasize the consumer related awareness programme whereby consumer ignorance could be dispelled with greater force. Similarly, consumer interest groups need to come forward to show the way to the consumer as to how they can protect themselves.

Rural marketing must not be viewed by the prospective as mere expansion of business. The rural marketing participants have a much bigger role to play. The y have not merely to push the sales but they have to contribute to the process of socio-economic transformation in the rural area falling which any foray in rural market would have to beat a retreat. They must understand that their contribution to rural development process would bring them large and permanent business.

The present legislative measures and provisions particulars the consumer protection act 1986 is found to be adequate but legislation and government agencies are not the total answer to consumer exploitation. It is the implementing part that needs a little more attention. The implementation machinery for consumer protection in Assam should be made more efficient to deliver the maximum relief to the consumers.

The consumer has also a vital role to play in order to uphold his rights and interest in the rural market. Consumers carelessness buying opens many doors for exploitation and unscrupulous sellers tend to see this as an opportunity to cheat. Mere legislative measure cannot protect the consumers and the role of the government will be limited unless the consumers becomes vigilant and asserts his rights in a responsible manner. Careful buying, a little more prudence and restraint on the part of the consumer's will prevent exploitation at the source and also strengthen the protection provided by legal agencies. This call for self awareness of the consumers. In the rural market of Assam only a well developed plan of consumer education and awareness programme can improve protective behavioral performances and this will act as an effective counter power against exploitation and unfair trade practices.

\section{REFERENCES}

1. Singh, L.P. Regulated Markets in India, New Delhi,1983. P.4

2. Cornot, Principles of Economics ,P.10

3. Chapman, Economics. Quoted by Jain, S.C, Principles and practice of Agricultural Marketing ,Bombay, 1991

4. Clark and Clark. , Principles of marketing 1947 P.7.

5. NCEAR, New perspective in marketing, New Delhi P.3.

6. Census report - Government of India.2011

7. Kotler, Philip., Principles of marketing, prentice Hall of India pvt. Ltd. ,New Delhi , 1982.P.666

8. Anderson, R Alam., The disadvantaged consumers, Newyork free press, 1975 P.3 


\section{INTERNATIONAL JOURNAL of RESEARCH -GRANTHAALAYAH

9. Verma, Y. and Sharma, C.K., Need of consumer education in India, Indian management, October, 1990. P.P 4-8

10. Srivinassan, N.P. and Murugan, M.S., Role of voluntary organization in promoting consumerism, October, 1990, P.10.

11. Sherlekar, S.A., Marketing management, Himalaya publishing house, Bombay, 1986. P.72.

12. Cotler, Philip ., op.cit.P.238.

13. Kothari, C.R., Research methodology, method and technique, Willey Eastern Limited, New Delhi, 1990.P.105.

14. Panda,N.R.,Consumer Education in Nagaland-A priority, Silver jubilee Magazine of Kohima arts college, 1992

15. Elhance, D.N., fundamentals of statistics, Kitab Mahal,Allahabad,1972.P.736Gupta,B.N., Statistics, Sahitya Bhawan, Agra, 1984. 